\title{
Valency constructions at work: a case study
}

\author{
Temenuzhka Seizova-Nankova*
}

\begin{abstract}
This is a corpus-driven analysis which aims at highlighting the complex behavior of $V+$ eye(s) collocation (1372 occurrences) drawn from the BNC, more specifically from Kilgarriff's WordSketch of the lemma EYE. Statistical scores are used to identify patterns of use in relation to relative frequency. As a result, some monovalent, divalent, and trivalent valency constructions are described. Such observations have important implications both for future research of language use as well as for foreign language learning and teaching.
\end{abstract}

Key words: corpus-driven analysis, embodiment, inalienable possession construction, hapax legomena, semantic network

\section{Introduction}

The paper is part of a bigger project (Seizova-Nankova 2016) and is built on the basic claim that there are no hard and fast boundaries between lexis and grammar. The question about the complex internal structure of V_N collocations (Bybee 2010; OCD 2002) is in the center of attention. The hypothesis that collocations with different bodypart terms seem to build a semantic network of constructions based on family resemblance is raised. This has been dealt with in the detailed study of the 25 top-salient V_hand(s) collocations (Seizova-Nankova 2016) and some of these findings find full support in the present research of close eye(s) collocation.

The term lexicogrammar has been used before but the methodology used here differs in important ways. Basic features of this approach are to do with recent developments in linguistics and more specifically the combination of Valency theory and construction grammar and the use of valency construction as a basic construct of the analysis.

It should be pointed out that we also draw some insight from Generative grammar as concerns the analysis of the genitive forms and their functioning in the clause as co-referential or not (and hence anaphoric or not) to the clause-subject.

Corpus-driven and corpus-based analyses are two approaches that have for the last few decades been extensively used in order to reveal new facts about language not possible before. Corpus-driven analysis is the more rigorous of the two as it draws conclusions directly inferable from corpus data and empirical evidence with little or no predetermined theoretical conceptions of

\footnotetext{
* University of Shumen, Department of English Studies, Shumen, Bulgaria
} 
language. What this means is that for observational and descriptive adequacy one basically relies on a representative corpus on which generalizations can be drawn. Cognitive tasks like hypotheses raising and testing, compare and contrast, detail noticing, problem solving, decision making are all necessarily applied in the process. However common these tasks are to all observers, when it comes to the interpretation stage, then the expertise of the researcher is of vital importance and comes to the fore. That is why the interpretation stage is set apart as a separate line of thought which is in fact open-ended. There are always things that have to be further explained, additional issues raised and new observations made, all of which are prompted by and found in the empirical data. In this type of analysis, you do not start with theory, then go to practice and back to theory again. On the contrary, all inspiration lies in the recurrent repetitions of utterances in context and only then comes the daunting part of interpretation.

Bodypart terms used in the $\mathrm{V}_{-} \mathrm{N}$ collocations seem to exhibit similar features in terms of language realization as valency constructions. These show enormous possibilities for metaphorical extensions of meaning in order to reflect personal experience, feelings and inner comprehension of the state of mind and the surrounding world of the individual. All that is done in a specific way depending on the bodypart term. However, generally speaking, each term contributes to the understanding of our experience as embodied. The notion of possession takes central position and on it different semantic contrasts in constructions are built. A type of inalienable possession construction among others is revealed in the paper which has so far not received a similar interpretation in the literature. Conclusions are borne out on the basis of corpus evidence.

The paper consists of three sections, conclusion, and appencices. Section 1 gives a quick outline of the procedure, section 2 includes the analysis proper of close eyes collocation and section 3 deals with the description of the valency constructions of the collocation. The appendices have been manually sorted and present repeated patterns of use illustrating the different constructions.

\section{The procedure}

We have applied the procedure described in the corpus-driven analysis of V_N collocations with the bodypart hand (Seizova-Nankova 2016). At the very beginning of the analysis is the tag which introduces metadata of the collocation and includes general information about its whole population. The number of occurrences of the collocation in the BNC amounts to 1372 hits. This is accompanied by the normalized frequency per million words. Besides normalized frequency, it includes also two other types of frequency: raw frequency and relative frequency. Raw frequency accounts for the number of occurrences of the use of the headword in the singular and plural form based 
on different morphological realization of eye, while relative frequency shows differences in the preferred options of use.

Straight after the tag and as a first approximation to the analysis comes the discussion of the lexicographic view using Oxford Advanced Learner's Dictionary (OALD online). It is then followed by an account of the quantitative valency considered as the most intuitive grouping of the attested examples in terms of number of participants involved in the situation. There can be situations with only one participant - in the case of the passive and ergative constructions, situations with two participants in which the NP with the headword eye(s) functions as PCU1 (or Complement II), and situations with three participants (the trivalent uses) in which a third participant functioning as PCU2 and marked as Complement III is introduced.

Next comes the Complement Inventory which shows variation in the complement realization types of Complement I, II and III.

The EXAMPLES section of the research includes tokens illustrating the Valency patterns that follow. The way complements combine is at most cases unpredictable so that information is of great importance.

\section{ANALYSIS of close eye(s) COLLOCATION}

Corpus: British National Corpus, Kilgarriff's WordSketch of lemma eye (2004).

\section{Close eyes Hits: 1372 (12.2 per million), 32 sg vs 1340 pl, $2 \%$ vs $98 \%$}

\subsection{The dictionary definition:}

http://www.oxfordlearnersdictionaries.com/definition/english/close1_1?q=close [transitive, intransitive] close (something) to put something into a position so that it covers an opening; to get into this position.

SYNONYM SHUT

eg I closed my eyes against the bright light.

OPPOSITE OPEN

Idioms

shut/close your eyes to something - to pretend that you have not noticed something so that you do not have to deal with it You can't just close your eyes to his violence.They seem intent on shutting their eyes to the problems of pollution.

with your eyes shut/closed - having enough experience to be able to do something easily I've made this trip so often, I could do it with my eyes shut. 
From what we read in the Oxford Advanced Learner's Dictionary online it becomes clear that only the trivalent use is given an example (I closed my eyes against the bright light). What is lost on the learner is the complex architecture (Jackendoff 2010, 2013) of the collocation. Synonymy and oppositeness are two basic sense relations which can be the object of further research between the lexemes of close, open and shut in the collocations with eyes but no clear idea of their similarities and differences can be formed based on the dictionary entry. One of the two idioms with close mentioned is with the [to_NP]-complement - You can't just close your eyes to his violence, while the other is expressed with the grammatical metaphor (with my eyes shut) as in I've made this trip so often, I could do it with my eyes shut and thus turning the otherwise habitual instantiation of an event into a nominalized phrase as complement to the particle with. This is found both with the verbs close and shut - (with) my eyes shut/ closed either with or without the particle as shown by the brackets. The corpus sheds more light on their uses and the number of variations and discourses concerned.

\subsection{Corpus sample of close eyes collocation}

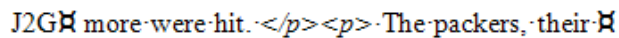

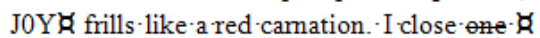

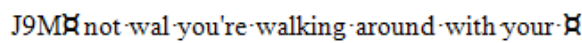
J54 $/$ roaring along the lanes. Sara closed her $\mathbf{R}$

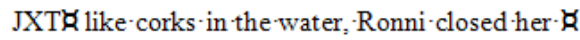
JXT down her champagne glass, then closed her $\not \not$

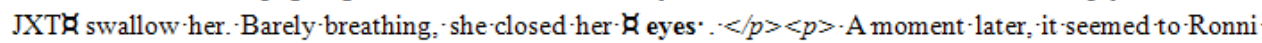
JXXßslightest notice of her-demand Laura closed her eyes', forcing herself to breathe slowly and $\not$.

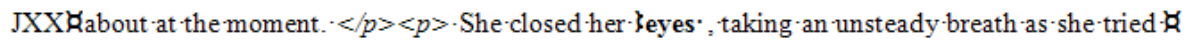

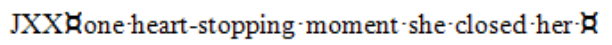

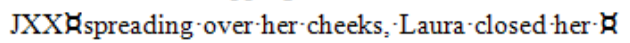
JXX her gown from her shoulder. Closing her $\not \mathfrak{k}$ JXXßhead-rest of the open sports car, closing her $\not \not k$

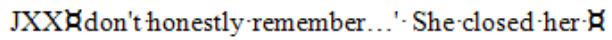
JXX the pile of beach cushions, ' closing ther $\not \varnothing$

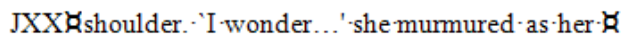
JXWk cover tonight. ' $</ p\rangle\langle p\rangle$. Lindsey closed her $\mathbf{R}$ JXWklazily on to her back, she floated with her $\not \not$ JXWkhappened to her willpower? She closed her $\not \mathbf{R}$ JXWkfelt the breath catch in her throat. His $\not \mathbf{R}$ eyes closed and their bodies tight against the $\not \mathbf{R}$ eye ' $\xi_{\text {against the }}$ light, and make-a note. II $\not x$ eyes - closed. I certainly-do in my patch. There $\mathbf{\not}$ eyes' - It seemed a million - years since the moming $\cdot \not$ eyes' and let herself-melt -against $\cdot$ him. It felt $\cdot \not$ eyes' and forced herself to breathe deeply and $x$ eyes', feeling quite faint at the extraordinary $\not \subset$ eyes' for a moment as they continued to revolve $\not \not$ eyes' as her senses' seemed to be spinning 'giddily ' $\mathbb{R}$ eyes' as 'she relished the cool breeze rustling $\cdot \not \subset$ eyes , leaning back against her remaining - pillow $\not \mathcal{R}$ eyes against the early-moming - sun, already $\not \not k$ eyes closed and she began drifting slowly off $\not \not k$ eyes' on the shocking realisation that she had $\not \subset$ eyes closed for a moment, frowning as the sound $\not \subset$ eyes', as if by doing so she could shut him out $\not \not h$ eyes' were closed, his face was pale. He could $\not \mathfrak{c}$

\subsection{Quantitative Valency}

M Movalent uses

1_3.JXX shoulder. 'I wonder...' she murmured as her eves closed and she began drifting slowly off ...

1_4.HTN- an eerie, human sound. Lucie's blacked eye was closed, and he 
seemed to take ...

D Divalent uses

1_1. JXSHis voice trailed to a halt. He closed his eves. Shiona was trembling uncontrollably ...

1_2. AP7you see; and she said, 'I then closed his eves and I laid down with him till the morning ...

1_2.a CCMmachine like this. Then he closed the eyes of the boy with the broken neck, and placed ...

1_5. K2Wpush the cross bar up. 'Gary had his eves closed and said he was going to die.' His ...

1_5.a. KEleyelid! Oh shit! Sorry! If he I hadn't had his eve closed, seriously, you know where your ...

\section{T Trivalent uses}

1_6. JY4a sob Ruth swallowed hard and closed her eyes to the burning sun overhead. And who would ...

16.a CKVthat. It was run like a club. It closed its eyes to what was going on'. Still, critics wonder ...

1_6.b HP0yodelling welcome. Nora closed her eyes on tears of joy. 'That noise!' she said ...

Note! The NP with head eye(s) functions as the only participant realizing Complement II in the monovalent uses of close eyes collocation. This way of describing the constructions gives a clear idea of the possibility of various alternations found in the corpus, most important of which is the ergative pair alternation.

\subsection{Complement Inventory}

I optional $[\mathrm{NP}]$

II optional

III optional

$$
[\mathrm{NP}] \mathrm{p},[\mathrm{NP}] \mathrm{a},\left[\mathrm{NP} \_\mathrm{V}\right. \text {-ed] }
$$

[PartP]

$$
\text { 1_1, 2, 5, 5a, 6, 6ab }
$$$$
1 \_1,2,3,4,5 \mathrm{a}, 6,6 \mathrm{ab}
$$

$1 \_6 a b$

Complement III realizations: the [PartP]-complement finds basically three complement types such as [against_NP], [to_NP], [to_wh-CL] and [on_NP] complements.

NB! Attested instances of ergative and passive constructions ([NP]a, [NP], ) make clause complement optional. In the present version of Valency theory, obligatory 
are those elements which are always realized as part of the construction (Herbst et al. 2008).

\subsection{Examples}

1_1. JXSHis voice trailed to a halt. HeI closed his eyesII. Shiona was trembling uncontrollably ...

1_2. AP7you see; and she said, 'II then closed his eyesII and I laid down with him till the morning ...

1_2.a CCMmachine like this. Then heI closed the eves of the boyII with the broken neck, and placed ...

1_3.JXX shoulder. 'I wonder...' she murmured as her eyesII closed and she began drifting slowly off ...

1_4.HTN- an eerie, human sound. Lucie's blacked eyeII was closed, and he seemed to take ...

1_5. K2Wpush the cross bar up. 'GaryI had his eyes closedII and said he was going to die.' His ...

1_5.a. KEleyelid ! Oh shit! Sorry! If he I hadn't had his eye closedII, seriously, you know where your ...

1_6. JY4a sob RuthI swallowed hard and closed her eyesII to the burning sun III overhead. And who would ...

1_6.a CKVthat. It was run like a club. ItI closed its eyesII to what was going on'. III Still, critics wonder ...

1_6.b HP0yodelling welcome. Nora I closed her eyesII on tears of joyIII. 'That noise!' she said ...

\subsection{Valency Patterns}

$[\mathrm{NP}]$ act-subj + verb/act $+[\mathrm{NP}]$

$[\mathrm{NP}] \mathrm{a}+$ verb/act

[NP] $\mathrm{p}+$ verb/act

$[\mathrm{NP}]$ act-subj + verb/act $+\left[\mathrm{NP} \_\mathrm{V}-\mathrm{ed}\right]$

$[\mathrm{NP}]$ act-subj + verb/act + [NP], [PartP]

\section{Valency Constructions}

At every level of the analysis the degree of abstracting away from the raw data increases until the level of Valency constructions. The important thing here 
is that constructions are a combination of specific information concerning language use in combination with generalizations thus effecting the combination of Valency theory (Herbst 2014, 2015) with construction grammar as found in the works of A. Goldberg (1995) and W. Croft (2003).

The valency constructions with close eye(s) collocation are varied and show a high degree of complexity comparable to constructions with V_N collocations with the lemma hand. The analysis includes monovalent, divalent and trivalent constructions.

A very important feature of the corpus is the use of the singular form of the lemma eye. It exhibits only 32 instances of use which makes $2 \%$ of the entire population, still in terms of variations in the constructions used and the meanings expressed they show great similarities with the plural form while differing mainly in respect to preferred options. This fact gives further details and contributes to building the semantic network (Goldberg, Jackendoff 2004) of the collocation under discussion. The realization of the singular nominal as Complement II shows variation: most frequent of which is the use of one, then come other realizations such as forms of the genitive his, the, the other, the same, the real. Here is an instance with an, eg. G0M spoke and four who listened, will close an eye again tonight? And of the three of us who ...

\subsection{Monovalent Constructions}

\section{The ergative construction}

In the construction the noun phrase with head the bodypart is the only complement. It fills the SCU slot and is often metonymically extended to mean the person oneself, hence it functions as a kind of AGENT to the lexical verb and at the same time maintaining the constructional meaning specific for the only participant of the ergative construction.

JXX shoulder. 'I wonder...' she murmured as her eyes II closed and she began drifting slowly off ...

SCU NP
$\left[\mathrm{NP}_{\text {actsubj }}\right.$

Here some examples (see App 5):

HA5possessed such a deep core of selfishness. Her eyes closed for a brief second as she drew all ...

H9Cwine down their throats. It was only as his eyes closed and he drifted into sleep that Corbett ... 


\section{The passive construction}

In the construction the noun phrase with head the bodypart is the only complement as well, but this time it expresses the AFFECTED semantic role to the lexical verb - that is, the person or thing that undergoes the action or has its state changed. This is accompanied with the morphological change of the verb into passive. The use of passive constructions allows speakers to organize stretches of discourse by placing figures other than the agent in subject position. There are 48 instances in the past tense and 11 - in the present tense (see App $4 a$ and $4 b)$.

HR7trees. I crawled over to the soldier. His eyes were closed. The gun fired again. It seemed ...

SCU NP
[NP $_{\text {pass-subj }}$
$\mathrm{VHC}_{\text {act: } 1}$
'AeFFECTED']_were closed

Some other examples:

G01corner, one eye on his quarry. The other eye had been closed for most of the fight by ...

HTN- an eerie, human sound. Lucie's blacked eye was closed, and he seemed to take

There are two readings of the construction - stative and dynamic, but it is often difficult to distinguish between them, except in special cases where still tilts the balance to the stative meaning as in eg. JYApeace.' She looked at him again. His eyes were still closed, and she smiled at her .....

\section{The imperative type construction}

Among the attested examples of the collocation we find the imperative type construction like Close your eyes! This is the only instance of construction realized by the imperative clause type which consists only of the collocation close_eyes, eg. FYVforehead, just above the orbits. 'Close your eyes,' says Tod to the patient, who, of course ...

$\mathrm{VHC}_{\text {act: }}$ PCU1
Close $_{\text {act- }}$ [NP 'AeFFECTED']

\subsection{Divalent constructions}

Different valency constructions are discussed but the divalent construction is considered to be the basic one, the prototype, in comparison to the other constructions.

The divalent constructions are considered as basic on the following counts: i) they are most commonly used, ii) they are instantiations of the prototypical 
event structure, and iii) they are found in different forms and configurations: either as independent clauses marked by a fullstop [.] or a comma [,] or as part of a serial clause construction.

Here are some examples with [.] (see App 1a for more examples):

FYYshoulder again. Slowly, Alina closed her eyes. Her face was as blank as a porcelain mask ...

FAScrazy, what does that make me? I close my eyes. Tell my children we move north tomorrow ...

FABjust showed his teeth. Tippy closed her eyes tightly. Just wait until she saw

Here are some examples with [,]

JXUmean?' He had momentarily closed his eyes, but now they snapped open. 'Yes, with ...

EAWHold up a finger at arm's-length, close one eye, and line your finger up with a picture ...

CH0Try the optic.' She closed her real eye, and opened the other. Her image of the ...

Here are some examples with [...V]

HRAbloody cloud again. Blunt closed his eyes and loathed Woolley. He locked his fingers ...

FAScannot hear. La lala la. See? I close my eyes and imagine the dark hills I would have ...

FABhands travel across her body, she closed her eyes and with them her mind. 'Oh, Happy ...

\section{The reflexive construction}

Possession is an important category which finds expression in reflexive construction where referent and bodypart (eyes in this case) coincide. That this is the prototypical realization is reflected in the preferred frequency of use. Still, there are differences from language to language. In English it is realized with a genitive form in Complement II which is co-referential with the SCU in the self-same clause. The bodypart is typically accompanied by the genitive forms of the personal pronoun (often called in grammars possessive pronouns). If it weren't for the genitive, the construction would be classified as iconic par excellence. But that is not necessarily the case. Other languages like Bulgarian, for example, differ from English in that respect, eg. Tya/toj/to zatvori ochi. (Тя/ той/то затвори очи).

JXSHis voice trailed to a halt. He closed his eyes. Shiona was trembling uncontrollably $\cdots$

SCU NP $\quad \mathrm{VHC}_{\text {act. } 2}$ PCU1
$\left[\mathrm{NP}_{\text {act-subj }}\right.$
'AGENT']_closed act-


Here are some more examples (see App 1)

JXVback against the pillows and closing his eyes. 'Witch! Have you no shame, tempting an ...

JXSagainst the pillows and, sighing, closed her eyes. She had thought she was healed, beyond ...

JXS She shuddered helplessly and closed her eyes. 'Jake... Oh, Jake...' Her voice trailed off ...

HYAfeels confident enough to close his/her eyes. Then a second and third person introduced ...

\section{The non-reflexive construction}

The non-reflexive construction includes different cases of realization.

- marked by the genitive form in the NP with head eye(s), which is however non-coreferential with the SCU in the self-same clause, i.e. it does not share the same referent but it refers to another referent: $I \neq$ his eyes as in eg. AP7you see; and she said, 'I then closed his eyes and I laid down with him till the morning ...

- the use of the indefinite article as in eg. G0Mspoke and four who listened, will close an eye again tonight? And of the three of us who

- he use of the definite article which forms a discontinuous constituent with the of-genitive in post-position (the eves of the boy with the broken neck) as in eg. CCMmachine like this. Then he closed the eves of the boy with the broken neck, and placed ...,

- the use of one, as in eg. EAW Hold up a finger at arm's-length, close one eye, and line your finger up with a picture ..., or otherwise by the definite article...

This makes for greater variation of Complement II in the construction. Consider:

AP7you see; and she said, 'I then closed his eyes and I laid down with him till the morning ...

\section{SCU NP $\quad \mathrm{VHC}_{\text {act: } 2}$ PCU1 \\ $\left[\mathrm{NP}_{\text {act-subj }}\right.$ 'AGENT']_closed ${ }_{\text {act- }}[\mathrm{NP}$ 'AeFFECTED']}

Here's another example:

CCMmachine like this. Then he closed the eves of the boy with the broken neck, and placed ... 


\section{The analytical causative construction with resulting attribute}

The construction exhibits the idea of inalienable possession which is however expressed in the PCU1 (Complement II) in which the [V-ed]-past participle part of the complement occurs in its passive form together with its subject whose head is the headword eyes. For the analysis of C II there are two possibilities - either to be treated as one [NP_V-ed] or as two complements [NP]_[V-ed] (Herbst, Schüller 2008: 125). The analysis of valency structure poses problems for which there is no obvious solution (ibid.). We have opted for the former analysis.

K2Wpush the cross bar up. 'Gary had his eyes closed and said he was going to die.' His ...

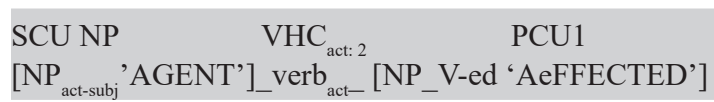

Here are some more examples:

G0Pher thighs with both hands. Julie had her eyes closed now and her head tilted back, so ...

G1Xwas still awake. Colonel Fergusson had his eyes closed and was breathing out through his ...

HSCconditions, wearing prisms, or had his/her eyes closed while listening to an auditory signal ...

The ASPECTUAL construction is here considered as a variation to the analytical causative with resulting attribute realized with the verb keep. Consider:

KEleyelid ! Oh shit! Sorry! If he I hadn't had his eve closedII, seriously, you know where your ...

The common feature is the exocentric phrase, the complex [NP_V-ed]complement functioning as PCU and consisting of a subject - lemma eye to the non-finite [V-ed] form of the verb close. The examples differ in the type of verb that takes the PCU as Complement II: have something done (to oneself - in the first case) and keep something done (to oneself again), with have being causative in nature and keep - aspectual. There are few examples with keep attested in the corpus, consider eg. HGKtime he went slowly but Maggie kept her eyes (tightly) closed. It was a long time since The AdvP is used inside Complement II and functions as an adjunct $-{ }_{\mathbf{A}}$ (tightly).

\subsection{Trivalent Constructions}

An additional complement, Complement III is added, realized by the [PartP]: against the light/the smoke. It is based both on the reflexive and the non-reflexive 
divalent construction, eg. B0Rbehind his remarkable new name, he closed his eyes on his troubles and tried to forget.

The use of the lemma eye in the singular shows almost the same construction types as the ones with the plural eyes, eg. J0Y frills like a red carnation. I close one eye against the light, and make a note..., or, eg. FS8the cigarette in his mouth and closed one eye against the smoke. 'Works for Kemp ...

One of the prevalent types is the [PartP]-complement with the particle to [to_NP]: 21 instances of use. Other realizations are [against_NP], [to_wh-CL] and [on_NP].

The meaning of the construction fluctuates easily and with no cost to the language user between the concrete (literal meaning) and abstract (non-literal extensions of) meaning (see App3a). They are all of the extended reflexive construction.

Complement III realization: to the bright moon that shone overhead, to the burning sun overhead, to aggression, to asylum and the pressures on our European..., to the drop beneath her, to the vital clue Rex Cunningham could, to everything but the sheer beauty of his, to the Livesey case, to unacceptable facts, to the miracle and mystery of life, to the darker currents in society, to the image, to the truth, to your activities, to the health facts, to it, to important normative issues, to that, to that garlic bread literally squelching..., to the fact, etc.

Consider:

HL3to measure, but the cost of closing our eyes to aggression is beyond mankind's power ...

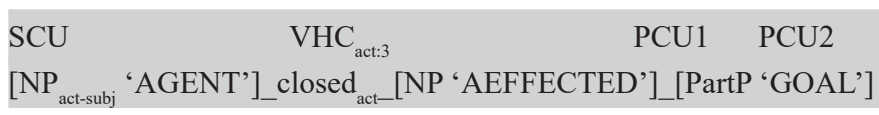

[against_NP] (see App 3b)

These can be divided into several groups according to the semantics of the complement to the particle.

1. Sources of light: against the sun, against the glare/2, against the silver dazzle that bounced ..., against the sudden change of light, against the pain his memories brought.., against the sun and against the confusion, against the early-morning sun...

2. Tears: against the sting of tears. against his ineffective tears. against the tears.

3. Parts of the body: breast, chest.

4. Abstract extensions of meaning: against a pull on her senses that set her .... 
..., against the river of heat his touch sent ..., against the unbelievable horror of it all ..., against her own unwanted memories., against a briefflare of irritation. against the flicker of fear running through..., against the sin. against the pain his memories brought...

5. There are also synonymous expressions of the construction in which Complement III is realized either with [to_NP] or [against_NP]: eg. JY4a sob Ruth swallowed hard and closed her eyes to the burning sun overhead. And who would ... and eg. CDXstaggering proportions. I closed my eyes against the sun and against the confusion ...

[to_wh-CL]:1 instance. Even though only one instance of this complement type is attested in the corpus, in our methodology hapaxes are important, eg.CKVthat. It was run like a club. It closed its eyes to what was going on'. Still, critics wonder ...

[on_NP]: 6 instances. (see App.3c)

Complement III realization: on the shocking realisation that she had, on the tawny liquid going down his throat, on the world's evidence, on tears of joy, on his troubles, on the image.

Only one of the six examples is, so to say, an instantiation of a concrete event, the others are abstract, metaphorical extensions of meaning. Thus, it seems we can, following OALD online, ascribe it to belong to the idioms. Our data, however, shows that classifying phrases as non-idiomatic and/or idiomatic is not feasible, for there are no hard and fast boundaries between these expressions. In fact, they are quite fuzzy. Here are two more examples:

HP0yodelling welcome. Nora closed her eyes on tears of joy. 'That noise!' she said ...

JXW cover tonight.' Lindsey closed her eyes on the shocking realisation that she had $\ldots$

\subsection{The resultative construction}

There is only one attested example found in the corpus of the type:

HGEa bit of all right.' And she closed one eye in a grotesque wink, leaving Sally-Anne $\ldots$

SCU NP
$\left[\mathrm{VHC}_{\text {act: } 3}\right.$ PCU1

The meaning of the construction is: $\mathrm{X}$ causes $\mathrm{Y}$ to move in order to bring about change of state $\mathrm{Z}$ realized by [PartP]: in a grotesque wink. The image below can be used as a visual representation and raises a point concerning the interrelation between spatial structure, expressed by gestures, and conceptual structure 
as reflected in language, or, in other words, 'how we talk about what we see' is important. We are not pursuing this line of thought now for lack of space (Jackendoff 2013; Seizova-Nankova 2016).

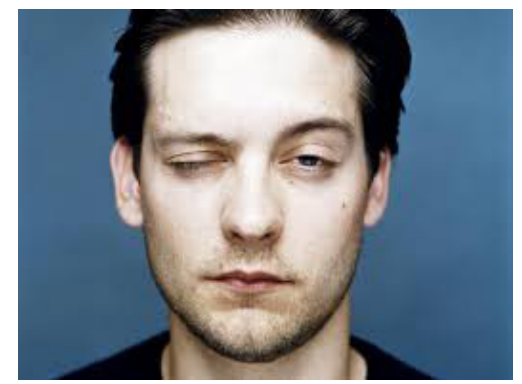

\subsection{Grammatical Metaphor (GM): (with) one's eyes closed}

$\mathrm{GM}$ is a phenomenon where the use of one grammatical form instead of another grammatical form is due to some semantic analogy between them. Two realization types are found in the corpus:

[NP], eg. J13leans back against his grey pillows, his eves closed and his face screwed up. I ask Eva ....and

[with_NP], eg. AYKhopping on one leg, going about with one eye permanently closed or trying to work with ..., K32first round victory had left him with an eye fully closed which eventually opened slightly ...(see App 6 for more examples).

The latter is by far the more frequent one.

\section{Conclusion}

The constructions discussed in this paper are based on the corpus-driven analysis and the objective of reflecting how specific information combines with greater generalizations is adequately described.

It seems that language is, on the one hand, all-embracing, whatever that may mean, and, on the other, easily adaptable to different ends and purposes, an adaptive social system. Judging from the research, analyzing language use inevitably brings to light some of these most remarkable features.

In the context of foreign language linguistics, the analysis also brings out features of the particular language under scrutiny (English) which can be similar or different to one's own language (Bulgarian). Collocations rank high in terms of problems in language acquisition. The lexical properties of linguistic units that deviate from basic grammatical rules are the crux of the matter. The new computation methods of approaching digital corpora face all these issues and help in gaining insights into the nature of language as a whole. 


\section{References}

Bybee 2010. Bybee J. Language, Usage and Cognition. Cambridge: Cambridge University Press, 2010.

Croft 2003. Croft W. Typology and Universals. Cambridge: CUP, 2003.

Goldberg 1995. Goldberg A. E. Constructions: A Construction Grammar Approach to Argument Structure. Chicago University Press, 1995.

Goldberg, Jackendoff 2004. Goldberg A., R. Jackendoff. "The English Resultative as a Family of Constructions". Language 80. 2004. 532-568.

Herbst et al. 2004. Herbst T., Heath D., Roe I. F., D. Götz (eds.) A Valency Dictionary of English: a Corpus-Based Analysis of the Complementation Patterns of English Verbs, Nouns, and Adjectives. Berlin: Mouton de Gruyter, 2004.

Herbst 2010. Herbst T. English Linguistics. A Coursebook for Students of English. Berlin/New York: De Gruyter Mouton, 2010.

Herbst, Schüller 2008: Herbst T., S. Schüller. Introduction to Syntactic Analysis. Tübingen: Narr, 2008.

Herbst 2014. Herbst T. "The Valency Approach to Argument Structure Constructions". Herbst T., Schmid H. J., S. Faulhaber (eds.). Constructions - Collocations - Patterns. Berlin/Boston: de Gruyter Mouton, 2014. 167-216.

Herbst 2015. Herbst T. "Why Construction Grammar Catches the Worm and Corpus Data Can Drive You Crazy: Accounting for Idiomatic and Non-idiomatic Idiomaticity". Journal of Social Sciences. 2015.

Jackendoff 2010. Jackendoff R. Meaning and the Lexicon. The Parallel Architecture 1975-2010. Oxford: Oxford University Press, 2010.

Jackendoff 2013. Jackendoff R. "Genesis of a Theory of Language: From Thematic Roles (Source) to the Parallel Architecture (Goal)" (Sort of an Intellectual Memoir).<https://ase.tufts. edu/cogstud/jackendoff/papers/GenesisofPA.pdf> [accessed on March 3th, 2016].

Kilgarriff 2004. Kilgarriff A., Rychlý P., Smrz P., D. Tugwell. "The Sketch Engine”. Proc. Euralex. Lorient, France, 2004.

OCD 2002. Oxford Collocation Dictionary. Oxford: Oxford University Press, 2002.

OALD online. Oxford Advanced Learner's Dictionary online. <http://www. oxfordlearnersdictionaries.com/definition/english/close1_1?q=close>.

Pencheva 2011. Pencheva M. Kognitivna lingvistika. Rechnik na ponyatiyata i terminate. Sofia: Universitetsko izdatelstvo Sv. Kliment Ohridski, 2011.

Seizova-Nankova 2016. Seizova-Nankova T. Lexicogrammar of V_hand(s) Collocations. A Corpus-Driven Analysis. 2016. 340 pp. ISBN 978-619-201-120-8.

\section{APPENDICES}

Appendix 1 of the divalent reflexive construction

JXSagainst the pillows and, sighing, closed her eyes. She had thought she was healed, beyond

JXS She shuddered helplessly and closed her eyes. 'Jake... Oh, Jake...' Her voice trailed off JXSclimbed into her own bunk and closed her eyes. I've done it! she thought with a

JXSHis voice trailed to a halt. He closed his eyes. Shiona was trembling uncontrollably JXVback against the pillows and closing his eyes. 'Witch! Have you no shame, tempting an JXUmean?' He had momentarily closed his eyes, but now they snapped open. 'Yes, with JXUpenny in his pocket.' Sarella closed her eyes. It was back to the same old theme. But 
J54 roaring along the lanes. Sara closed her eyes. It seemed a million years since the morning JXUtragic scene he leaned back and closed his eyes. It was after midnight. She was conscious JXUmattered at first...' He closed his eyes. 'I guess it must have been difficult for JXU's very sweet.' Sarella closed her eyes . She could imagine the three of them at JYBmuttered behind her. Kathleen closed her eyes . The room was a bloodbath, all of them JYBcystic fibrosis.' Kathleen closed her eyes . Now it all fell into place, the child JYBor your new lover?' She closed her eyes . Oh, damn, she thought, how would she tell JY0 'Let me think.' Irene closed her eyes . 'Pershore - near Pershore. Barkton - Berkton JY8sardonically, standing up. Paige closed her eyes . That made it even worse. Yet she would HRAWoodruffe laid down his fork and closed his eyes. Rogers cleared his throat. 'Going HRAbloody cloud again. Blunt closed his eyes and loathed Woolley. He locked his fingers HRAhim his flask, but Lambert just closed his eyes. 'They let these sausages up pretty high HRAas that,' Kimberley said. He closed his eyes. 'Now piss off and leave me alone.' He

Appendix 1a of divalent constructions ending with [.]

JXSclimbed into her own bunk and closed her eyes. I've done it! she thought with a JXUpenny in his pocket.' Sarella closed her eyes. It was back to the same old theme. But J54 roaring along the lanes. Sara closed her eyes. It seemed a million years since the morning JXUtragic scene he leaned back and closed his eyes. It was after midnight. She was conscious JXUmattered at first...' He closed his eyes. 'I guess it must have been difficult for JXU's very sweet.' Sarella closed her eyes. She could imagine the three of them at JYBmuttered behind her. Kathleen closed her eyes. The room was a bloodbath, all of them JYBcystic fibrosis.' Kathleen closed her eyes. Now it all fell into place, the child JYBor your new lover?' She closed her eyes. Oh, damn, she thought, how would she tell JY0 'Let me think.' Irene closed her eyes. 'Pershore - near Pershore. Barkton - Berkton JY8sardonically, standing up. Paige closed her eyes. That made it even worse. Yet she would HRAWoodruffe laid down his fork and closed his eyes. Rogers cleared his throat. 'Going HRAhim his flask, but Lambert just closed his eyes. 'They let these sausages up pretty high HRAas that,' Kimberley said. He closed his eyes. 'Now piss off and leave me alone.' He

Appendix 2 of the divalent construction with singular head eye:32 instances J0Y frills like a red carnation. I close-one eye against the light, and make a note.

HRAhim. Who's that?' Rogers closed one eye and peered up. 'Is that God?' The breadthrowers

HTN- an eerie, human sound. Lucie's blacked eye was closed, and he seemed to take HTYthrough the air. Spike closed his eye and again lost consciousness. Blake HGEa bit of all right.' And she closed one eye in a grotesque wink, leaving Sally-Anne HJGthumb and index finger, and closing one eye, usually the wrong one. Why do we AYKhopping on one leg, going about with one eye permanently closed or trying to work with ADXtheory requires that the observer closes one eye .The cone of vision The cone of vision A8Cthe eleventh round when McDonnell's right eye was all but closed, though the fighter 
ALJ A battered man in a woollen hat, one eye almost closed by a bruise, was appealing ALLpoliceman's back philosophically and closed one eye . Constable Campbell rounded the corner

BN3completely exhausted. I had lost two teeth, one eye was closed, and an ear torn. Yet, $\mathrm{McNab}$

B1XHe broke Sonny's nose and closed his left eye . He began to work on the body, aiming for BLXthe more obvious technique of closing the eye, it is no longer able to monitor the predator G1Mwas blistered from the hot coffee and one eye was closed. The other glared malevolently G0Mspoke and four who listened, will close an eye again tonight? And of the three of us who G01corner, one ey e on his quarry. The other eye had been closed for most of the fight by EAWHold up a finger at arm's-length, close one eye , and line your finger up with a picture KDAthing I found was, if you just close your eye and then open it again, your contact lens K32first round victory had left him with an eye fully closed which eventually opened slightly KEleyelid ! Oh shit! Sorry! If he hadn't had his eye closed, seriously, you know where your CH0Try the optic.' She closed her real eye, and opened the other. Her image of the CR6side as if he was thinking, closing one eye and giving his little grin. 'Tomorrow's CB8piece of plastic on a window, close one eye and trace the outlines of what you see. C85was purpling down the left side and one eye was closed. He bellowed something which CDT. The simple answer is to close the same eye whenever a car approaches; that is your FRHagain for the child and closing his red-hot eye 'You speak of stopping,' said Simon F9Xkeep the world still?' She closed her eye again before she levered her body upright FEVoverlapping views we receive. Closing one eye and then the other reveals the same scene FU5crystal cave. Silence and sootfall. A last eye being closed. I pray to find myself again FS8the cigarette in his mouth and closed one eye against the smoke. 'Works for Kemp FSJthings to do, oh yes!' Here he closed one eye and smiled at me. 'Now go to your squire

Appendix 3a of the trivalent construction with [to_NP]-complement

JY4a sob Ruth swallowed hard and closed her eyes to the burning sun overhead. And who would

HL3to measure, but the cost of closing our eyes to aggression is beyond mankind's power HHWshort term. It is no good closing our eyes to asylum and the pressures on our European HH8groping for the nearest bloom, closing her eyes to the drop beneath her. The rose didn't H8Tof the Tyrrell Society, he had closed his eyes to the vital clue Rex Cunningham could HA9arms slid around her and she closed her eyes to everything but the sheer beauty of his ANLhis pipe out. 'It is tempting to close our eyes to the Livesey case but, say what you will AN8suspect you are less likely to close your eyes to unacceptable facts.' 'Oh, surely ALHnever become so worldly that we close our eyes to the miracle and mystery of life. May A7Lthe desire of filmmakers to close their eyes to the darker currents in society, to make G15tumbling over his forehead. She closed her eyes to the image, waiting to hear only the G0Fcynical about is the way everyone closes his eyes to the truth. I was only teasing you because

G0NWhat do you think I mean? I've closed my eyes to your activities long enough. Well, they 
EC2... The government can no longer close its eyes to the health facts. It is condoning promotion

K8Rthe abyss and then resolutely closed his eyes to it. If Rose was bearing a child, that KSTn't look! So No. I just try and close my eyes to it Yeah. and I walk indoors. But ooh CM2lead one to believe that he is closing his eyes to important normative issues. Notoriously CL4part of the poetry of creation. Close your eyes to that and you bar a means of communication

CDRcorn-on-the-cob without salt or butter. Close your eyes to that garlic bread literally squelching

FCVsection 16(2). We cannot close our eyes to the fact that if the arguments advanced JY4doing that,' she added softly, closing her eyes to the bright moon that shone overhead.

Appendix $3 \mathrm{~b}$ of the trivalent construction with [against_NP]-complement JY8rise and fall of his chest, and closed her eyes against a pull on her senses that set her JY5nodded, and she looked away, closing her eyes against the sting of tears. 'Then JY6fine-honed beauty of that chest. She closed her eyes against it. 'Put your shirt back HR4 'Who cares?' Maxim sat back closing his eyes against his ineffective tears. George HGTto hold on to her composure, closing her eyes against the tears. He would have to appear HGE'I know,' said McAllister, closing her eyes against her own unwanted memories. HJHAdjusting her position and half closing her eyes against the sun, she too stared out over H82sounds. Either she must close her eyes against this or she must enter. Unnerved HA9 'Anyone around?' She closed her eyes against a brief flare of irritation. She HA9you, Shannon Lea?' She closed her eyes against the flicker of fear running through HA9then settled on her hip, and she closed her eyes against the river of heat his touch sent A0LFloating beyond the foam, she closed her eyes against the sin. The problem, she BPDthe columns? Jack wondered. He closed his eyes against the unbelievable horror of it all GW2arms and escape his anxieties. Closing his eyes against a warm breast, he became a child GVTsaid. 'Mm,' she grunted, closing her eyes against the glare. After a pause he said G17waver in a haze of heat. Jehan closed his eyes against the glare. In his belt he had a CEHlifted her face to the sun, half closing her eyes against the silver dazzle that bounced CEHstepped back into the office, closing her eyes against the sudden change of light. Jock C8A Richard shook his head and closed his eyes against the pain his memories brought. CDXstaggering proportions. I closed my eyes against the sun and against the confusion

Appendix 3c of the trivalent construction with [on_NP]-complement JXW cover tonight. Lindsey closed her eyes on the shocking realisation that she had HH0poverty. Willie watches his brother close his eyes on the tawny liquid going down his throat

H8Rnumb beyond her last of sense, closed her eyes on the world's evidence And into pillows HP0yodelling welcome. Nora closed her eyes on tears of joy. 'That noise!' she said B0Rbehind his remarkable new name, he closed his eyes on his troubles and tried to forget. FP7small vineyard.' Pascoe closed his eyes on the image for a moment. A hillside under 
Appendix 4a of the passive construction/past tense

JYApeace.' She looked at him again. His eyes were still closed, and she smiled at her

HR7trees. I crawled over to the soldier. His eyes were closed. The gun fired again. It seemed

HTYhad stopped. He sat opposite Blake. His eyes were closed and his mind was elsewhere.

HGTread his profile in the half-light. His eyes were closed. Was he asleep? 'Robyn

HJHslowing to normal, her body quietening. His eyes were closed, and she was surprised when

HH9and thought it looked nice. Gran's eyes were closed. Emmie put the tray down on

HH9and thought it looked nice. Gran's eyes were closed. Emmie put the tray down on

H7Win saving her he had been hurt. His eyes were closed and pallor gave his weathered

HWEhim. Peggy sank into a chair. Her eyes were tightly closed, her mouth wide. He

HWUemergency room he appeared deeply comatose: his eyes were closed and he did not react to noxious

H8Sthe gentle rise and fall of his chest. His eyes were closed, and his face had a lazy, satisfied H8Jglass on a table at his side. His eyes were closed and he looked completely at

H8Nclasped around her head. Alan saw that her eyes were closed. She had not heard the door

H8Nslowing to normal, her body quietening. His eyes were closed, and she was surprised when

H0FAnne's voice) but I was too far gone. My eyes were closed, and that tongue, oh that tongue ACBpulled Gazzer's head up by his hair. Gazzer's eyes were closed. 'Open your eyes,' said ACWas the fabric itself. She was happy. Her eyes were closed, and she was smiling. Just AE0light at the window grew stronger, but their eyes were closed. She awoke from a light A7Jfrom the coldness of her extremities. Her eyes were closed against the glare of lights AR3trolley, eased him down on to the carpet. His eyes were closed, his face was an ashen colour

BPDwires linked his body with machines. Ken's eyes were closed and his breathing was horribly

BPDdown at his stepfather almost angrily. His eyes were closed now. 'Don't try him again BLXher hand. No respiration was visible, the eyes were closed, the mouth gaped and the paws GWFmarked her torn robe in many places and her eyes were closed, but she was breathing. GV3hands. He did not look at the keys. His eyes were closed. He was in another world. His GVTglanced at the young man beside him. His eyes were closed; he had passed into the body GUDwith his head resting against the arm. His eyes were closed and his breathing noisy. GUGthere, looking down at him. The old man's eyes were closed, the thin lids veined, mauve G14methylanthranilate in the chicks' bills when their eyes were closed arid showing that this did

G15the glass in front of his nose. Urquhart's eyes were closed, the lashes like black feathers G01pulled out the corkscrew. The tramp's eyes were closed but Magee used his thumb and G06fingers. She sat still, and I believe her eyes were closed. Nobody could sit so still EWCthe gap and squatted beside him. Bigwig's eyes were closed and his lips pulled back from CE9Wisharts kept giving her a look but her eyes were closed and she looked very serene C9W- and she could not see anything as her eyes were tightly closed. But she could hear 
CK0little face was a mass of wrinkles. Its eyes were closed. It had strangely long, fine CLDwashed by the rain spots. She knelt. Her eyes were closed, her lips moved. She crossed CLDheavy-knit dun brown sweater. His eyes were closed. It might get to be a bit of FRYwas on the ground, beside the line. His eyes were closed and he did not move when they FRHjostled them there, and she saw that his eyes were closed and that he had gone gray with FR0out from the edge of the fallen slab. His eyes were closed and his expression blank. F99a dark, easy drifting. She realized her eyes were closed. But there seemed to be a dim F99motionless, his face turned up to the chains; his eyes were closed, and fire burned clear and F99turning him over on to his back. Adam's eyes were closed, in some state that looked FB9Your pretty head.' But Hugh's brown eyes were closed and his martyred Saint Sebastian FABHer mouth felt as dry as a bone and her eyes were closed against the intrusive light FSEnature.' Kiku shook her head. Her eyes were closed. She moved against him and, FSJdownstairs. We lifted the captain's head. His eyes were closed and his face was a terrible

Appendix 4b of the passive construction/past tense

J17softness of his hair. My wrist aches; my own eyes are closed. Back and forth go my thoughts

A0Yon the back with hands at the side, the eyes are closed (coins or cotton wool on the HGUmuch response, and much of the time his eyes are closed. But Babur figures his voice HGF'O, she who twitches and shouts when her eyes are closed,' said the seal. 'What was the HJH?' 'If you must.' Clare closed her eyes again. 'Well, what I was going to

B1Jnot the same as the peace on a face whose eyes are closed in prayer. To say this is not B74when they are peeking as well as when their eyes are closed. However, active sleep is confined

B74looks as though the length of time their eyes are closed determines the amount of active EVAwhen less is demanded of them and their eyes are closed - almost as if they were drifting CBFGraham, of County Durham police. 'Her eyes are closed and her nose and mouth are badly

FU5me to hear: I am waiting in the dark. My eyes are closed, my throat is clogged growing

Appendix 5 of the ergative construction

HA5possessed such a deep core of selfishness. Her eyes closed for a brief second as she drew all

H9Cwine down their throats. It was only as his eyes closed and he drifted into sleep that Corbett

H9C'Absolve me, Domine!' he muttered as his eyes closed and his soul was extinguished.

CECwould stay with me during that time.' His eyes closed as he recalled the confrontation ...

CJXsilences but while she was talking that her eyes closed-and her shallow breathing became ...

F9X's what I'd like to know.' Lacuna's eyes closed for a few seconds. When they opened ...

FSE. The sun was warm and he was tired. His eyes closed and he slept. It was still

FSleffect. Harry stayed with her until her eyes closed and then went to see if there was ... 
FPUup at the white ceiling again. Slowly his eyes closed and his head dropped quietly on ...

Appendix 6 of grammatical metaphor, two types:[NP $\}$ and [with_NP]

$[\mathrm{NP}]: 1$

BP0that lay the tragedy. She lay, her eves closed and smiling, surrendered to death

CE5stared at the pale face of his friend, the eves closed but moving restlessly beneath the J13leans back against his grey pillows, his eyes closed and his face screwed up. I ask Eva ...

[with_NP]: 9

H8Ninto the bathroom. Carolyn sat with her eyes closed listening to the water running and H8Nwas lying on the floor smoking, with her eyes closed. 'That's because she made you. How ASEfinished her tea and now leant back with her eyes closed and the swollen ankle propped up H0Fstood beside the streaming panes with her eyes closed, willing herself to capture something

H0F. Irena simply sat, quite often with her eyes closed. From time to time one of the women H9Vantipathy he always aroused in her. With his eyes closed, concentration firming his features

ADYfelt odd. I clung hard to a sapling with my eyes closed, waiting for things to get better A0Gus who cannot make a daisy chain with our eyes closed - and who could forget the daisyspangled

AS3mph on the wrong side of the M8 with your eyes closed.The haul up the corrie takes 